The study proposal has been approved by 9thSeptember University Ethical Committee. Workers will be asked for informed consent before the survey.

Result We will include 370 cleaning professionals in the study. The prevalence of respiratory, skin and musculoskeletal symptoms will be determined, stratified for different cleaning professionals and their socio-demographic variables. We expect all results in October 2017.

Discussion The main outcome is the estimated prevalence of work-related disorders in cleaning professionals and associated occupational risk factors in Turkey. We will also analyse the effect of these disorders on the related prevalence of disability in work and daily life. Based on the results, interventions for prevention of will be recommended.

\section{THE DEVELOPMENT OF OCCUPATIONAL HEALTH AND SAFETY IN THE UNIVERSITY LABORATORIES IN TURKEY}

${ }^{1}$ A Bolukbas*, ${ }^{2} \mathrm{OA}$ Ergor. 'Dokuz Eylul University, Faculty of Engineering, Environmental Engineering, Izmir, Turkey; ${ }^{2}$ Dokuz Eylul University, Faculty of Medicine, Department of Public Health, Izmir, Turkey

\subsection{6/oemed-2018-ICOHabstracts.838}

Introduction The significant obligations have become valid by the change in the legislation with the Occupational Health and Safety Law in Turkey. Thereafter, besides private sector, public institutions have to establish and apply occupational health and safety systems. Therefore, occupational health and safety systems have been started to establish in the universities including the university laboratories which include several potential hazards such as chemical substances, biological materials and electrical systems. The aim of the study is to observe the development of occupational health and safety in the universities.

Methods The study has been conducted in a laboratory in Environmental Engineering Department of Dokuz Eylul University. The risk assessment method based on $5 \times 5$ matrices and Failure Mode and Effect (FMEA) have been used. The 5 $\times 5$ matrix risk assessment was modified with respect to daily dosage for workers and taken measurements like engineering, administrative and personal. FMEA has been selected due to the detectability factor in order to observe the awareness of the workers.

Results The $5 \times 5$ matrix risk assessment evaluates existing situation by considering the working hours of the workers with hazard and the positive effects of precautions. FMEA evaluates the risks as there is no precautions and the workers are exposed to the hazard during all shift. As a result of the risk assessments, to prevent the chemical, biological, physical, ergonomic, psychosocial and working environment risks precautions were taken with respect to the regulation; however, they aren't adequate. The system was established but is not completely and properly worked.

Conclusion To conclude, education and drill have to be conducted and emergency plans must be prepared. Working processes with chemicals and biological samples have to be defined and the workers have to be trained. Laboratories and storages have to be organised according to state of the art technologies. Preventive health services have to be provided for workers. The occupational health and safety system in the laboratories has to be improved for efficient protection.
126

BASELINE URINARY FINDINGS IN YOUNG ADULTS AT RISK OF CHRONIC KIDNEY DISEASE OF UNDETERMINED CAUSE IN NORTHWESTERN NICARAGUA

${ }^{1}$ ET Smpokou*, ${ }^{1} B$ La Rosa Garcia, ${ }^{2}$ Le Blond, ${ }^{3}$ J Glaser, ${ }^{4} \mathrm{~A}$ Camacho, ${ }^{5} \mathrm{D}$ Faber, ${ }^{4}$ A Aragón, ${ }^{1} \mathrm{~J}$ Norman, ${ }^{6} \mathrm{~N}$ Pearce, ${ }^{6} \mathrm{D}$ Nitsch, ${ }^{1,4,6} \mathrm{M}$ González, ${ }^{1} \mathrm{~B}$ Caplin, ${ }^{7} \mathrm{~J}$ Morton. ${ }^{1}$ Centre for Nephrology, University College London (UCL), London, UK; ${ }^{2}$ Royal School of Mines, Imperial College London, London, UK; ${ }^{3}$ La Isla Network, Chicago, Illinois, USA; ${ }^{4}$ Research Centre on Health, Work and Environment, National Autonomous University of Nicaragua, León, Nicaragua; ${ }^{5}$ La Isla Foundation, León, Nicaragua; ${ }^{6}$ Non-Communicable Disease Epidemiology, London School of Hygiene and Tropical Medicine, London, UK; ${ }^{7}$ Health and Safety Laboratory, Health and Safety Executive, Harpur Hill, Buxton, UK

\subsection{6/oemed-2018-ICOHabstracts.839}

Introduction There is an epidemic of Chronic Kidney Disease of undetermined cause $(\mathrm{CKDu})$ in Central America causing the death of tens of thousands of agricultural workers. We have undertaken a community-based cohort study to identify factors associated with loss of kidney function in young adults at high risk of CKDu. The aim of this analysis was to characterise the associations between urinary findings at baseline and loss of kidney function (eGFR) over the follow-up period.

Methods We analysed urine samples from 350 apparently healthy men and women (ratio 3:1) from 9 communities in northwest Nicaragua. Semi-quantitative analysis using urine test strips (Siemens Multistix10 SG Reagent Strips) was performed on stored frozen samples. Albumin and creatinine levels were quantified using bromocresol green and Jaffe methods, respectively. Metals were analysed by ICP-Mass Spectrometry. Test strip findings were compared between the group with more stable function and the group with declining eGFR. Linear regression was used to investigate the associations between urinary metal concentrations and change in eGFR.

Results The majority of study participants had normal test strip results however there was an association between increased proteinuria (but without evidence of elevated albumin) in the declining group in comparison to the stable group $(\mathrm{p}=0.03)$. Aluminium and cadmium levels were above accepted limits compared to the general population, but no association with loss of eGFR was found.

Discussion A urine strip test is unlikely to be useful in identifying those with early CKDu. The positive urine strip test for protein in the absence of albuminuria in a proportion of those with declining kidney function likely indicates the presence of other proteins of tubular origin. Our data suggest high levels of overall exposure to aluminium and cadmium but do not suggest these metals have a causal role in loss of kidney function.

\section{PRELIMINARY STUDY OF THE PREVENTION CULTURE IN COMPANIES HAVING MORE THAN 100 WORKERS IN CÔTE D'IVOIRE}

${ }^{1} \mathrm{AJ}$ Eba* 1,2BY Yeboué-Kouamé, 1,3JH Kouadio, ${ }^{2} \mathrm{JS}$ Bonny. ${ }^{1}$ Département Santé au Travail, Laboratoire de (Bio) Toxicologie et Hygiène Industrielle, DPPSST, CNPS 01 B.P. 317 Abidjan, Côte d'Ivoire; ${ }^{2}$ Département de Médecine du Travail, Médecine légale et de Toxicologie, UFR SMA, Université FHB, BPV 166 Abidjan, Côte d'Ivoire; 'Département de Biochimie Microbiologie, UFR Agroforesterie, Université JLG, BP 150 Daloa, Côte d'Ivoire

\subsection{6/oemed-2018-ICOHabstracts.840}

Introduction Safety and health culture is about the perception shared by the organisation's members towards safety and the effort to maintain the safety and health level in the 